\title{
The Library and Information Service
}

\section{Mental Fealth Inquiries}

Members may be interested to know that the Library's special collection of these inquiries has now grown to fifty in number. Although most of the reports are for reference purposes only, in a number of cases there is a copy available for loan. A list giving details of the collection is avallable from the Library.

\section{Peychiatric Associations of the World}

As a result of the many enquiries recetved by the College Library for details of psychiatric associations in other countries, a register of this information is held in the Library. This has been updated over the past months and printed copies giving information on over ninety assoclations world-wide are now available from the College Publications Department. Psychiatric Associations of the World. 3rded OP29, price £5.00.

\section{Blake Marsh Lectures and Lecturers}

Minutes of the Royal Medico-Psychological Association Council for November 1963 record that "a handsome legacy of about $\$ 20,000$ in shares has been made to the Association by the late Dr Blake Marsh" and in July 1964 the Education Committee recommended "an annual lecture on the subject of mental subnormality be instituted". Since 1967 there has been a lecture every year with the exception of 1988 and most of the lectures have been printed in the British Journal of Psychiatry.

R. G. Blake Marsh was a member of the Royal Medico-Psychological Association from 1929-1960. He was Secretary of the Mental Deficiency Section from 1943-51 and Chairman from 1954-57. He worked at Claybury in Essex, Leavesden in Hertfordshire and Bromham Colony in Bedfordshire.

The Library has compiled a bibliography of the Blake Marsh Lectures, copies of which are available on request from the Library.

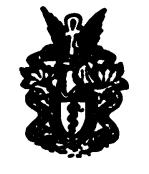

The

Royal Medico-Psychological Association

THE MEST

BLAKE MARSH LECTURE

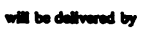

PROFESSOR C. E. DENT

$\infty$

Mental Deficiency

and Amino Acid Metabolism

a

The Royal Society of Medicine, West Hall,

1 Wimpole Street, London, W.I

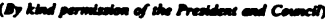

TUESDAY, 7th FEBRUARY, 1967, at 6.00 p.m.

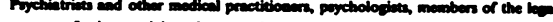

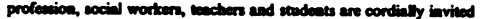

Adriteicion withoor ticket

A. A. MONRO, M.D., Th.D, D.P.M Henovery Gemend Secenerery 